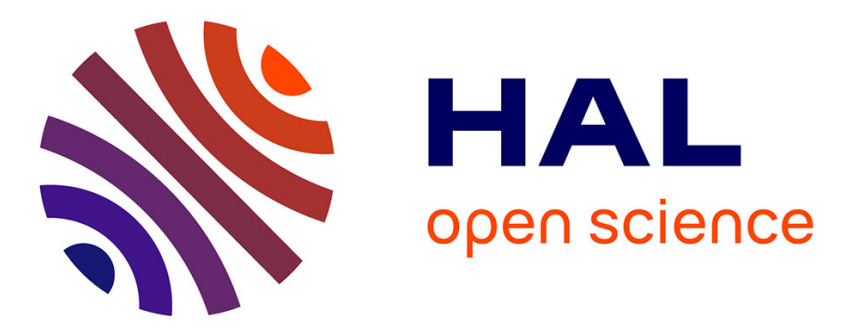

\title{
Anchoring unsorted e-sources about heritage artefacts in space and time
}

\author{
Gamze Saygi, Jean-Yves Blaise, Iwona Dudek
}

\section{To cite this version:}

Gamze Saygi, Jean-Yves Blaise, Iwona Dudek. Anchoring unsorted e-sources about heritage artefacts in space and time. Lecture Notes in Computer Science, 2018, ITN-DCH Final Conference proceedings, 10605, pp.167-178. 10.1007/978-3-319-75826-8_14 . halshs-01674351

\section{HAL Id: halshs-01674351 \\ https://shs.hal.science/halshs-01674351}

Submitted on 2 Jan 2018

HAL is a multi-disciplinary open access archive for the deposit and dissemination of scientific research documents, whether they are published or not. The documents may come from teaching and research institutions in France or abroad, or from public or private research centers.
L'archive ouverte pluridisciplinaire HAL, est destinée au dépôt et à la diffusion de documents scientifiques de niveau recherche, publiés ou non, émanant des établissements d'enseignement et de recherche français ou étrangers, des laboratoires publics ou privés. 


\title{
Anchoring Unsorted E-Sources about Heritage Artefacts in Space and Time
}

\author{
Gamze Saygi, Jean-Yves Blaise, Iwona Dudek \\ UMR CNRS/MCC 3495 Modèles et simulations pour l'Architecture et le Patrimoine \\ Centre National de la Recherche Scientifique \\ Campus CNRS Joseph Aiguier - Bât. Z', 31 chemin Joseph Aiguier, \\ 13402 Marseille Cedex 20, France. \\ (gamze.saygi, jean-yves.blaise, iwona.dudek) @map.cnrs.fr
}

\begin{abstract}
Thanks to citizen-side contributions, heritage scientists can now quite often gather large amount of spatio-temporal data about heritage artefacts. In the context of minor heritage collections, which often slip through large-scale heritage programs, accessing such data sets may be a decisive turn in uncovering important clues, or significant relationships in and across collections. In other words, the "citizen science" paradigm seemingly opens a whole new range of opportunities at research level (e.g., enrichment of data, comparative analyses, multidisciplinary annotations) and for collection holders (e.g., networking, "intangible" museums).
\end{abstract}

Yet, due to the nature of such data sets (e.g., heterogeneity in the wording, in the precision, verifiability issues, contradictions), these opportunities also raise challenges, in particular when wanting to foster cross examinations by heritage scientists. The global objective of our research is to better weigh how the nature of citizen-side contributions can impact the way information can be recorded, formalized, and visualized. In this paper a clear focus is put on the space and time parameters: geo-visualization, and spatio-temporal data visualization. The paper introduces a series of open-source geo-visualization solutions that have been designed for use in the context of information sets harvested from citizenside e-sources, and that help document minor heritage assets.

The results we present show that hybrid visualizations can act as a basis for comparative reasoning and analysis, but also that the core service we should manage to offer is definitely an infovis one: getting to understand (at last) what we really know (and ignore). 
Keywords: Information visualization $\cdot$ Spatial data $\cdot$ Temporal data $\cdot$ Cartography $\cdot$ Geo-visualization $\cdot$ Information filtering $\cdot$ Cultural heritage $\cdot$ Citizen science.

\section{Introduction}

Minor heritage comprises edifices/objects/landscapes, in other words vernacular heritage artefacts which are the result of past actions carried out by local society/inhabitants, by know-how, artisanship, acquired and transmitted from one generation to another. Indeed, they were important components of everyday life at a time, but of today, they generally slip through large heritage programs or documentation initiatives. It is a particular research topic as items are usually not well documented, or documented in a very erratic way.

Heritage scientists and cultural actors cannot really count on existing and comprehensive research work when they want to analyze minor heritage. Nevertheless, as of today, there is a large number of citizen-side contributions (e.g., personal or associative web sites, blogs, or crowdsourced data sets) dedicated to the minor heritage. However, when looking at these contributions, there is neither any connection between them nor any structure. So, what if we pull those information sets together in such a way that cultural/scientific professionals can better analyze them? Moving from this point forward, this research focuses not only on "minor" heritage, but also on citizen science and its potential, in an attempt at deciphering the context of "human" beyond the artistic value of heritage artefacts. Correspondingly, our research effort questions the relevance and benefits of the citizen science paradigm in the context of minor heritage with a specific focus on spatial and temporal information. The aim of this research is not to depict one particular artefact but to gain some understanding of information trends in a large collection of artefacts, i.e., spotting patterns in the data sets that can then be analyzed and ultimately related to historical, geographical, climatic or other factors, and to cross-examine evidence about heritage collections.

On the other hand, one could think that a visual model in terms of threedimensional rendering seems to be the nature of cultural heritage visualization, [1] but there is a large amount of (often ill-defined) spatio-temporal information hidden beyond the imagery. Consequently, a complementary formalism is required for a comprehensive understanding of spatial characteristics of heritage edifices, their evolution, and more generally to address the why and how questions that need to be examined when trying to recount the stories of artefacts and of their interrelations in what Kienreich [1] calls an information space. In that context, information visualization (infovis), which is defined as "computer supported, interactive, visual representation of abstract data to amplify cognition" [2], its potential to do cross-examination, and uncover illiterate information. Intersecting infovis and carto/chrono-graphy, this paper puts a clear focus on the space and time parameters: geo-visualization, and spatiotemporal data visualization. It introduces a series of open-source geo-visualization solutions that have been designed for use in the context of information sets harvested from citizen-side e-sources, and that help document minor heritage assets. 
Yet, one thing has to be stated clearly: this paper's claim is not that the visualization solutions we propose help analyze the heritage artefacts themselves. Our claim is that the emergence of the citizen science paradigm requires pushing to the fore solutions helping to analyze and cross-examine the data behind these artefacts, with its heterogeneity, lacks, and contradictions. The contribution focuses on an early-stage possibility: distributing the data in time and space, and trying to highlight the informational patterns such a visualization bias allows for.

\section{State-of-the-art}

Recent research in spatio-temporal information visualization has found application platforms in a wide spectrum of fields, some of which extends to temporal data visualization with a physical spatial reference. Some researchers in the geographical domain initiated the joint use of information visualization and cartographic representation (contour lines, relief shading, or orthoimages) by superimposing vector graphics [3], color-coded notation [4, 5], combination of the two former [6, 7] or animated colored graphs $[8,9]$ as spatio-temporal information layers supporting enhanced information visualization. Similar to those, many innovative visualization techniques are applied in the context of flow analysis [10, 11]. The work of [12] for instance analyses the potential benefits of animation on both static maps and the space-time cube, whereas the study of [13] visualizes spatio-temporal information dynamically as 3D animation superimposed on a cartographic background. In Beaude [14] travel times of commuters are analyzed by means of a combination of three visuals solutions: a geo-tagged topographic map, a "topological space" in which durations are represented by distances to the center point, and a time series represented as a histogram. The noteworthy contribution of Boyandin [15] brings a novelty to flowmaps by combining the potentials of geo-visualization and abstract temporal information visualization as a hybrid solution. The study results in an easier interpretation of spatiotemporal patterns and of their mutual relations. In parallel to this approach, some interactive platforms $[16,17]$ offer an integrated visualization of choropleth mapping and geotagging based on the temporal queries defined by users in order to analyze diverse regional dynamics. This integration is reinforced in some other studies [18, 19] by embedding graph and chart displays coupled with temporal animations or interactive navigation [20].

There is also a growing interest for diverse spatio-temporal information visualization techniques embedded in a cartographical solution. As an exemplification, Goovaerts [21] criticizes the use of three-dimensional visualization applied to cartography, Thakur [22] introduces a "data vases" visual metaphor based on kite diagrams in order to visualize multiple time, Bell [23] reuses the "data rose" visualization introduced by Huang [24] to superimpose geo-visualization and ringmaps. Similarly, Zhao [25] deciphers the potential of integrating multiple visualizations, i.e. cartographic representation with ringmaps, horizontal and vertical views in different scales (national, regional, etc.) by adding extrusion value for temporal events. In addition, Tominski [26] employs color coded 3D trajectory bands embedded on a 2D map and 
complements the visualization with a circular time display. And, Slingsby [27] experiments a link between treemaps, spatial treemaps, raster maps and road maps. The above mentioned interactions allow cross-filtering of information by applying different spatial and temporal variable combinations.

A few applications [28, 29] have also targeted data sets in relation with historical sciences: they appear as very promising for geo-localizing information, and [30] adds a simultaneous visualization of temporal events. Nevertheless, these examples incorporate spatial anchoring of information in-forms of geo-localization, but they consider the temporal dimension only in the context of a linear, punctual and determined actions. More specific to the cultural heritage domain, geo-localization of information proved its importance with a number of examples [31-34] in the field, some of which offering enhancement with simultaneous temporal information visualization. Nevertheless, detaching spatial information from temporal information bounds the understanding of cultural heritage information. In fact, spatio-temporal information visualization is a challenging issue in that application field due to the heterogeneous, imperfect, fuzzy and sometimes uncertain nature of temporal data. Some studies [35, 36] already take into consideration uncertainties and heterogeneity of temporal data, and Blaise [37] explored a number of visualization options, i.e. combination of twodimensional spatial representations with diverse temporal visualization (timeline, concentric time) in order to represent architectural changes of a group of edifices throughout the time. Although those studies draw attention to the particularities of spatio-temporal visualization for cultural heritage studies and their prospected needs, they do not offer a generic framework that would match a variety of use cases.

Thorough evaluation of the in-house approaches shows that most visualization solutions in which both spatial and temporal data are of concern to analysts, there is a general tendency to segregate them in different views. Our contribution in comparison to the aforementioned studies focuses on experimenting a hybrid space + time visualization solution, adapted to information sets extracted from citizen-side unsorted esources, and concerning a large amount of minor heritage artefacts.

\section{Implementation and interactive user platform}

The global objective of our research is to better weigh and assess how the nature of citizen-side contributions can impact the way information about minor heritage can be recorded, formalized, and visualized. One of the first developments we have engaged is a series of open-source geo-visualization solutions that have been designed for use in the context such information sets, and that help document minor heritage assets. The idea was to try to see what how unsorted raw data as available in web content (whatever the origin and target of the web pages) can act as a tool for the (re)interpretation of minor heritage. The research process started with the cumbersome task of analyzing and pulling together large and unsorted data sets (web pages mainly). That first task lead to a structuring of the data that offers a level of flexibility suitable to the harvesting context (e.g., heterogeneity, lacking elements), and focusing on the "localization" or "anchoring" of the information in time and space. 
In a second stage we designed open-source geo-visualization solutions allowing for what the whole process is about: comparative reasoning. Shortly said, the ambition of these open-source visual solutions is to support analysts in their effort to pull together and make sense of unsorted, raw evidence. The visualization platform builds on the famous mantra of Shneiderman [38]: "overview first, zoom and filter, then details-on-demand", and aims to do implicit data filtering through user interaction. It does not only distribute (in space and time) e-sources systematically, but allows analysts to uncover expected or unexpected patterns and correlations among the information set. In this section we first present the test case and in particular the data we cope with, and then comment on some of the visual solutions.

\subsection{Harvesting and structuring the data}

The research encompasses three heterogeneous collections: edifices, movable objects (ethnographic collections from the MuCEM, Museum of European and Mediterranean Civilizations) and intangible heritage (practices, craftsmanship). Naturally the way items of these three collections are localized (in time and space) is uneven, and an issue as such, but in this paper we shall focus on the first aforementioned collection, composed of 1066 rural chapels (fig.1) located in the south-east of France (Southern Alps, région Provence-Alpes-Côte d'Azur), distributed in 340 communes ${ }^{1}$. The spatiotemporal data brought together is quite significant in terms of quantity (over $2500 \mathrm{e}$ sources), and can be described as imperfect, incomplete, and heterogeneous both in terms of determinacy and of origin. Besides, there is neither any connection between them nor any predefined structure since most of the e-sources originate from scattered local initiatives (e.g., individuals recounting a journey, group of persons interested in the local history). E-sources are stored with typological markers showing the origin of the producers, from "official" web sites to individual blogs (fig.2).

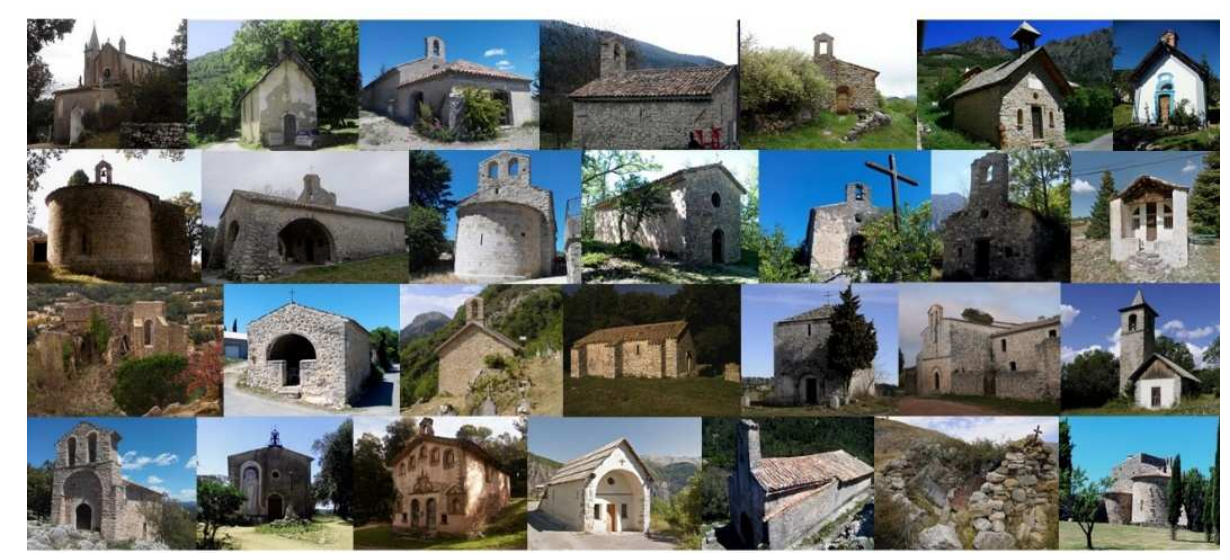

${ }^{1}$ The communes are the lowest level of administrative division in the French Republic. 
Fig. 1. Imagery representing archetype of (some) edifices within the collection.
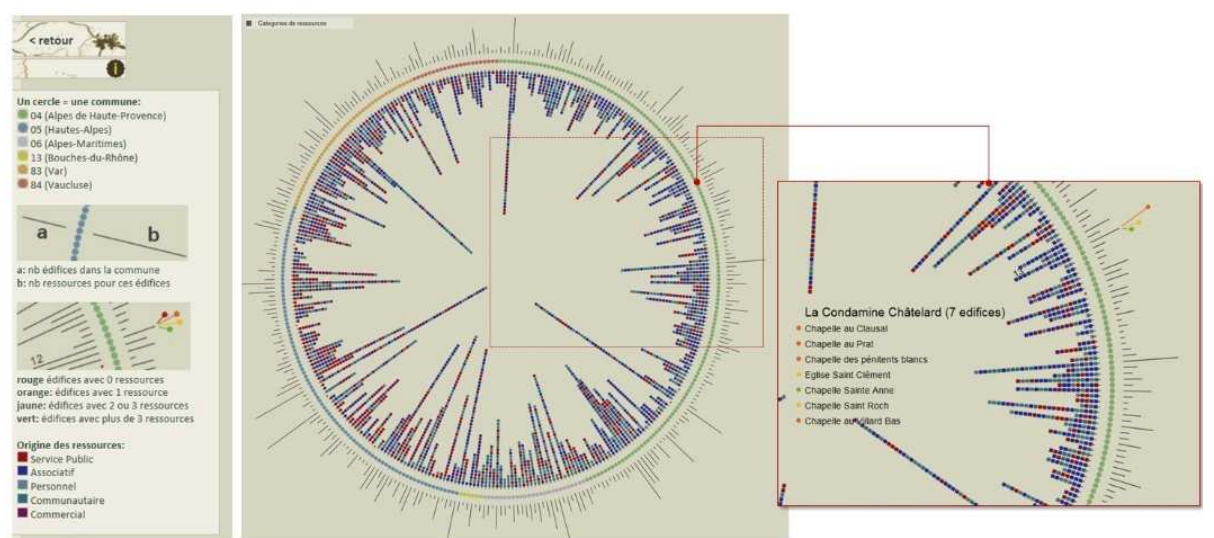

Fig. 2. A visualization of e-sources distributed by commune. Each commune is represented by a small circle composing the overall circular diagram, the colors of these circles differentiate the administrative structure communes belong to. Lines running from the circles outbound measure the number of edifices per communes (the longer the line, the highest amount of edifices). The small squares making up the lines inward have a color code according the e-source category, and length of the lines show the amount of e-sources. A selection by the user of one the circles results in the opening of a list of edifices per commune, with for each of them a number of e-sources. Significant remarks can be made when analyzing the visualization: no systematic relation of the number of edifices to the number of sources, a detectable difference in the origin of sources between communes on the right (green circles) and communes on the left-down quarter (blue circles), substantial differences across edifices of the same commune, etc.

The harvesting task aimed at providing for each edifice the following indications:

- Geospatial characteristics: geographical location, with an assessment of quality (04 scale), typological markers, orientation, altitude, toponymical variations.

- Temporal characteristics: anchoring in time of the artefact's creation or foundation, with an assessment of contradictions and a data model storing on one hand the verbal indication as found in the source and a transfer to a tuple of integers, and a recording of cyclic events (e.g., votive festivals).

- Imagery and other qualitative indications such as alternative names.

It has to de said that these indications are not always available, can be worded in an imprecise way (e.g., ...the edifice was located along the narrow valley close to the stream...) or can be contradictory, hence it created one of the next challenges: creation of explicit graphical semiology. 


\subsection{The visualization effort}

The aim of the visualization effort goes beyond the localization of artefacts on maps: what is targeted is to support information analysis and data quality assessment, as an overly above a background cartography. In terms of technology, the platform combines RDBMS, HTML/js scripting, and a cartography part developed over the leaflet web library [39]. The whole platform thereby remains fully "in line" with the very essence of citizen science initiatives.

The resulting interactive geo-visualization facilitates exploration by information filtering in various zoom levels and offers the following services: (i) examining each edifice individually, (ii) evaluating groups of edifices focusing on a specific commune, (iii) comparing individual edifices or communes with each other by applying

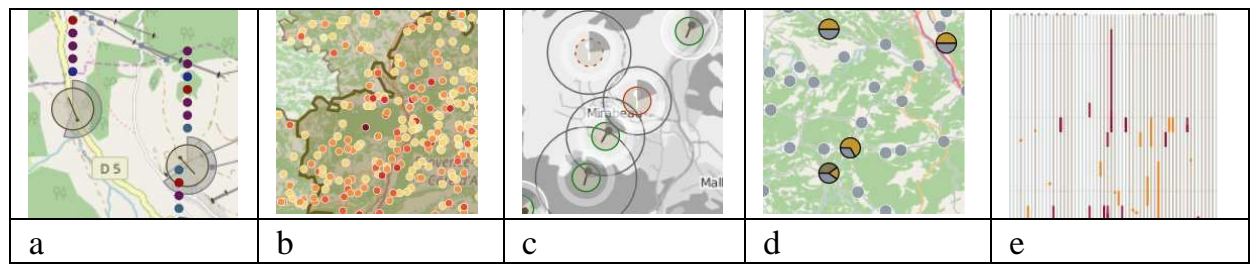

different spatial and/or temporal information filters, (iv) interpreting the overall dataset by detecting relations, similarities and differences in regional scale. Table 1 summarizes the various visual solutions we have developed and tested.

Table 1. Comparison of the available information layers in different geo-visualization solutions

\begin{tabular}{|c|c|c|c|c|c|}
\hline Available information layers/access options & a & $\mathrm{b}$ & $\mathrm{c}$ & $\mathrm{d}$ & $\mathrm{e}$ \\
\hline Geographical location & $\checkmark$ & $\checkmark$ & $\checkmark$ & $\checkmark$ & $\checkmark$ \\
\hline Quality of localization & $\checkmark$ & $x$ & $\checkmark$ & $x$ & $x$ \\
\hline Implantation (relation with a setting) & $x$ & $x$ & $x$ & $x$ & $\checkmark$ \\
\hline Orientation & $\checkmark$ & $\checkmark$ & $\checkmark$ & $\checkmark$ & $x$ \\
\hline Altitude & $\checkmark$ & $\checkmark$ & $\checkmark$ & $\checkmark$ & $x$ \\
\hline Visual (thumbs) & $\checkmark$ & $\checkmark$ & $x$ & $\checkmark$ & $x$ \\
\hline Ordinal/linear time & $\checkmark$ & $x$ & $\checkmark$ & $x$ & $\checkmark$ \\
\hline Cyclic time & $\checkmark$ & $x$ & $\checkmark$ & $x$ & $x$ \\
\hline Amount of e-sources & $\checkmark$ & $x$ & $\checkmark$ & $x$ & $\checkmark$ \\
\hline Origin of e-sources & $\checkmark$ & $\checkmark$ & $\checkmark$ & $\checkmark$ & $x$ \\
\hline Quality of information & $\checkmark$ & $x$ & $\checkmark$ & $x$ & $\checkmark$ \\
\hline User-side free interaction & $x$ & $x$ & $\checkmark$ & $x$ & $x$ \\
\hline Pre-defined controlled zoom levels & $\checkmark$ & $\checkmark$ & $x$ & $\checkmark$ & $\checkmark$ \\
\hline
\end{tabular}

The solutions we have experimented implement the concept of implicit filtering at two levels: using the geographical localization itself, and using the representation of that localization (zoom level). Shortly said, several issues have been at the heart of our developments: the age-old question of combining space and time in a unique vis- 
ual component, the use of alternative models of time and of alternative filtering by zoom levels, the notion of information patterns, and of course pitfalls to overcome when facing incomplete or ill-defined pieces of data (e.g., contradictory temporal information, imprecision of localization). The following figure (fig.3) illustrates (some of) the actual services provided.
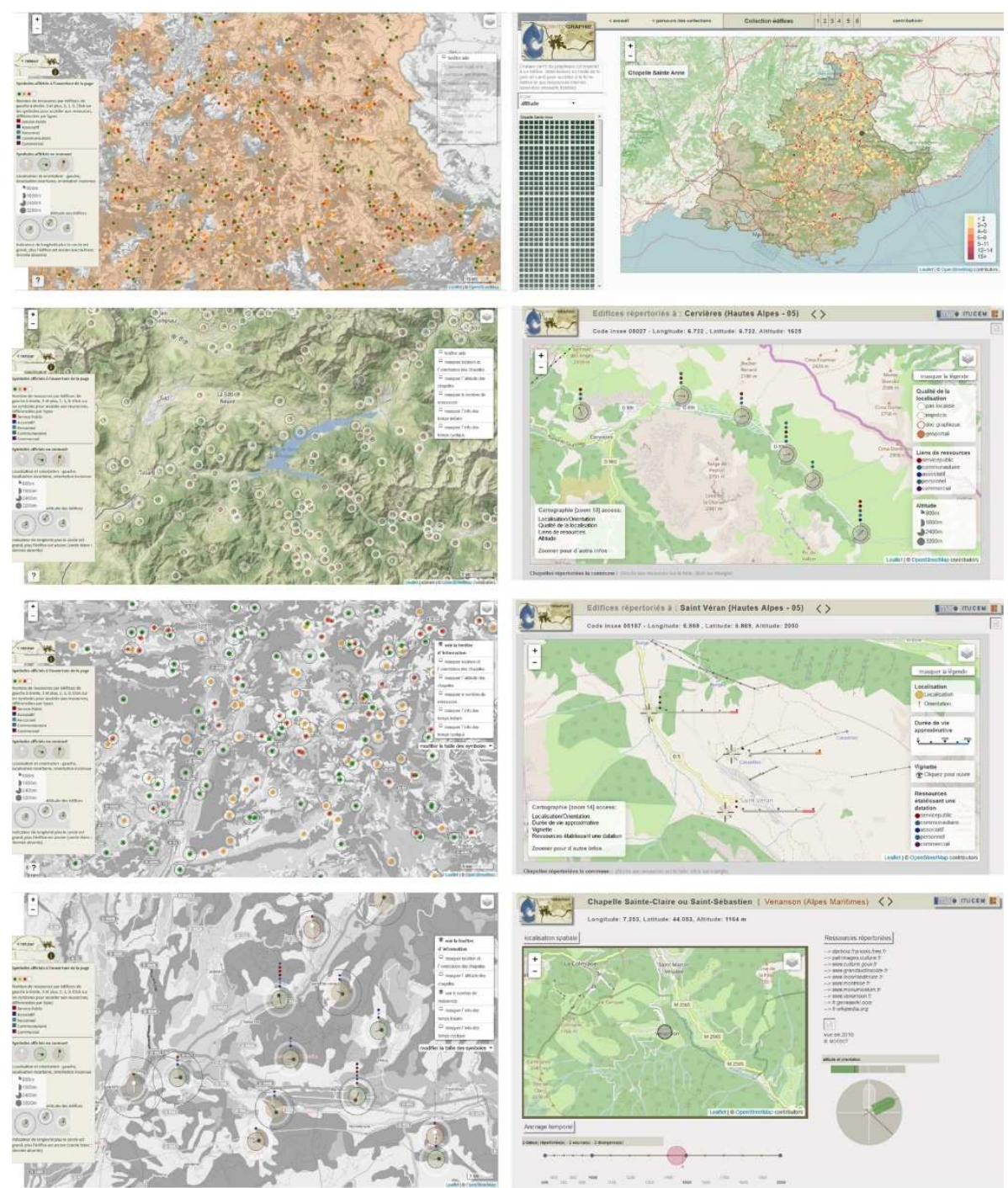
Fig. 3. Examples of open-source geo-visualization solutions in two main variations: on the lefthand side a user can superimpose all or some spatio-temporal information for cross comparison according to his/her preference, whereas on the right-hand side, target information is predefined and information layers are displayed/hidden following zoom level change by the user. The background cartography is subject to change in both cases.

\section{$4 \quad$ Evaluation and limitations}

The overall implementation process has been straightforward to handle, and found convenient for organizing interaction between a map and other components of the web interface. Nonetheless, it derives the necessity for the designer to invest time on programming interactions. In addition, some limitations need to be made clear:

- The platform allows enhancing cartographical layer with other components but it has a rather limited graphic vocabulary.

- The readability of the "abstract" semiology representing overlaid spatio-temporal information patterns is significantly impacted by the cartographic background layer selected by the user. For instance, some layers may be visible in black and white Open Street Map (OSM) background while they are not in regular OSM.

- We experimented embedding multiple cartographic backgrounds, named "tiles" in the leaflet architecture (OSM, OSM B\&W, IGN's géoportail, Wikimedia, etc.). It can be seen as an advantage for different readings of information patterns but alters the performance when adding numerous tiles (downloading time becomes costly).

- We faced an inconsistency problem regarding the different projections provided by diverse open-source repositories. For instance, the boundaries of communes provided by public sources do not persistently overlap with OSM.

- The overlapping of symbols - also an age-old problem in cartography - remains an open issue. At this stage, we offer user-side interaction that allow resizing of the semiology, typically in the case of close vicinities. The state-of-the-art seems to prove that an ideal solution remains to be found for redistribution / masking /grouping of the overlapping symbols.

- The density of the information layers added on top of the cartographic background leads to large files, embedding an important set of client-side events handling and js functions. At this stage, the scalability of the implementation remains questionable: the reuse of the technological pipeline should be a concern if wanting to extend the experiment to significantly larger collections.

Finally, we also carried out an experimental evaluation of the main cartographic solutions in order to investigate the coherency of the system with human cognition, i.e., its efficiency as a communication channel. It allowed us to compare two approaches for information filtering, i.e., predefined controlled zoom levels (the zoom level implicitly filters the information layers) and a classic user-side free interaction (user-side selection of information layers to display).

Seven human evaluators, used to heritage as a domain but with different backgrounds, were asked to spot information patterns (comparing the amount of sources 
for a set of edifices for instance), to carry out basic tasks (finding an edifice with a given information pattern for instance), and in the case of maps with predefined controlled zoom levels to associate information layers with a given zoom level.

In user-side free interaction mode, the majority of the rates show that readability of ill-defined localization was more convenient than the readability of ill-defined temporal data. Ultimately testers were asked to rate the readability and efficiency of the cartographic products in a more flexible way, and here the variety in background of testers was an important and positive aspect of the evaluation as it showed that beyond some specific shortages of the platform, named by most testers, a number of choices and designs are diversely judged. The relevance, the information retrieval capabilities of the platform clearly would require different "ways of doing" matching the different types of understanding of the testers. Naturally we need to say that the overall evaluation should be seen as a preliminary one, we acknowledge the necessity to further evaluate, and develop overall implementation accordingly.

\section{$5 \quad$ Conclusions and future works}

This research aims at answering to the question of how information harvested from citizen-side contributions about time and space, given their very nature (e.g., imperfections, heterogeneity), can be profitable for comprehensive analysis by heritage scientists such as cross-examination. It is found out that although there is a growing interest on applying visualization solutions/models for evaluating spatial and temporal information, most segregate spatial information from temporal information, which might create misconceptions especially concerning heritage spaces' dynamic characteristics which continuously evolve in time. Our contribution differs from the aforementioned approaches by providing a hybrid information retrieval platform, designed to allow for the identification of information patterns in a wide minor heritage collection. This requires a comprehensive solution allowing both evaluating peculiarity of each artefact and comparisons with one another.

The introduced space+time geo-visualization solutions targeted minor heritage assets for which there is a lack of comprehensive analytical information. Evaluation results show that provided open-source visualization solutions embedding various spatial and temporal attributes in a platform, can allow scientists to benefit from hybrid visualizations as a basis for comparative reasoning and analysis. By this way, one can uncover illiterate information patterns and correlations in the information by filtering and combining spatio-temporal variables.

We now plan to experiment collaborative 3D data acquisition in connection with the developments carried out in our research unit. What is ahead is also collecting real-life experiences and testimonies, beyond existing sets of e-sources, through crowdsourcing-like initiatives.

Acknowledgements. This research is funded by the région Provence-Alpes-Côte d'Azur regional authorities, under the program entitled Territographie (www.map.cnrs.fr/territographie), conducted in co-operation with MuCEM (Museum 
of European and Mediterranean Civilizations). The authors are indebted especially to Édouard de Laubrie from MuCEM for his continuous support and collaboration.

\section{References}

1. Kienreich W (2006) Information and knowledge visualisation: an oblique view. MiaJournal, vol.0, No.1.

2. Card S (2007) Information visualization. In: The Human-Computer Interaction Handbook: Fundamentals, Evolving Technologies, and Emerging Applications, Lawrence Erlbaum Assoc Inc., pp 509-543. doi:10.1201/9781410615862.ch26.

3. Kääb A, Huggel C, Fischer L, Guex S, Paul F, Roer I, Salzmann N, et al. (2005) Remote sensing of glacier- and permafrost-related hazards in high mountains: an overview. Natural Hazards and Earth System Sciences, 5, European Geosciences Union, pp 527-554. doi:10.5194/nhess-5-527-2005.

4. Pritchard H, Murray T, Luckman A, Strozzi T, Barr S (2005) Glacier surge dynamics of Sortebræ, east Greenland, from synthetic aperture radar feature tracking. Journal of Geophysical Research, 110. doi:10.1029/2004jf000233.

5. Lang O, Rabus BT, Dech SW (2004) Velocity map of the Thwaites Glacier catchment, West Antarctica. Journal of Glaciology, 50, pp 46-56. doi:10.3189/172756504781830268.

6. Star C (2006) Jakobshavn Glacier Flow in the Year 2000. NASA Scientific Visualization Studio, SVS Image Server.

7. Joughin I, Howat IM, Fahnestock M, Smith B, Krabill W, Alley RB, et al. (2008) Continued evolution of Jakobshavn Isbrae following its rapid speedup. Journal of Geophysical Research, Vol. 113. doi:10.1029/2008jf001023.

8. Robert S (2007) Le paysage visible de la Promenade des Anglais à Nice: essai d'une représentation cartographique dynamique. Mappemonde, No.86.

9. Kobben B, Becker T, Blok C (2012) Webservices for Animated Mapping: The TimeMapper Prototype. Lecture Notes in Geoinformation and Cartography, pp 205-217. doi:10.1007/978-3-642-27485-5_14.

10. Geertman S, de Jong T, Wessels C (2003) Flowmap: A Support Tool for Strategic Network Analysis. In: Planning Support Systems in Practice, (eds): Geertman S, Stillwell J, Berlin: Springer Verlag, pp 155-175. doi:10.1007/978-3-540-24795-1_9.

11. Konjar M, Boyandin I, Lalanne D, Lisec A, Drobne S (2010) Using flow maps to explore functional regions in Slovenia. $2^{\text {nd }}$ International Conference on Information Society and Information Technologies - ISIT 2010.

12. Biadgilgn DM, Blok CA, Huisman O (2011) Assessing the Cartographic Visualization of Moving Objects. Momona Ethiopian Journal of Science, 3, $\mathrm{N}^{\circ} 1$, pp 80-104. doi:10.4314/mejs.v3i1.63687.

13. Antoni JP, Klein O, Moisy S (2012) La discrétisation temporelle. Une méthode de structuration des données pour la cartographie dynamique. Cartes \& Géomatique, Revue du Comité Français de Cartographie, 213, pp 27-31.

14. Beaude B, Guillemot L (2012) Commuting Scales. Cartographie dynamique d'accessibilité temporelle. Mappemonde; $\mathrm{n}^{\circ} 105$.

15. Boyandin I, Bertini E, Bak P, Lalanne D (2011) Flowstrates: An Approach for Visual Exploration of Temporal Origin-Destination Data. Eurographics / IEEE Symposium on Visualization (EuroVis 2011), vol.30, n.3, pp 971-980. doi:10.1111/j.1467-8659.2011.01946.x.

16. Interactive mapping of American presidential political votes http://dsl.richmond.edu/voting/interactive/ 
17. Interactive library of regional population dynamics http://stats.oecd.org/OECDregionalstatistics/\#story=0

18. Banos A, Lacasa J (2007) Spatio-temporal exploration of SARS epidemic. Cybergeo: European Journal of Geography, Systèmes, Modélisation, Géostatistiques, document 408. doi:10.4000/cybergeo.12803.

19. de Oliveira MG, de Souza BC (2012) GeoSTAT - a system for visualization, analysis and clustering of distributed spatiotemporal data. Proceedings XIII GEOINFO, November 2527, 2012, Campos do Jordao, Brazil, pp 108-119.

20. Kapler T, Wright W (2005) GeoTime Information Visualization. Information Visualization, Vol. 4, No. 2. doi:10.1109/infvis.2004.27.

21. Goovaerts P (2010) Three-dimensional Visualization, Interactive Analysis and Contextual Mapping of Space-time Cancer Data. $13^{\text {th }}$ AGILE International Conference on Geographic Information Science.

22. Thakur S, Rhyne TM (2009) Data Vases: 2D and 3D Plots for Visualizing Multiple Time Series. Advances in Visual Computing Proc. ISVC 2009, Springer, pp 929-938. doi:10.1007/978-3-642-10520-3_89.

23. Bell K. (2011) Visualizing Crime - A "Data Rose" Blooms. Directions magazine.

24. Huang G. et al (2008) Geovisualizing Data with Ring Maps. Esri ArcUser.

25. Zhao L, Forer P, Harvey AS (2008) Multi-Scale and Multi-Form Visualisation of Human Movement Patterns in the context of Space, Time and Activity: From Timeline to Ringmap. AGILE 2008 Conference, Girona, Spain.

26. Tominski C, Schumann H, Andrienko G, Andrienko N (2012) Stacking-Based Visualization of Trajectory Attribute Data. IEEE Transactions on Visualization and Computer Graphics 18, vol.12, pp 2565-2574. doi:10.1109/tvcg.2012.265.

27. Slingsby A, Dykes J, Wood J (2008) Using treemaps for variable selection in spatiotemporal visualisation. Information Visualization, 7, Palgrave Macmillan, pp 210-224. doi:10.1057/palgrave.ivs.9500185.

28. The Growth of Newspapers across the U.S.: 1690-2011. http://web.stanford.edu/group/ruralwest/cgi-bin/drupal/visualizations/us_newspapers

29. MyHistro / the Hundred Years' war. http://www.myhistro.com/story/the-hundred-yearswar/34325/1\#!war-during-the-rule-of-charles-v-67299

30. Visualizing emancipation. http://dsl.richmond.edu/emancipation

31. World Heritage List interactive map. http://whc.unesco.org/en/interactive-map/

32. Cultural Heritage Map of Turkey. http://turkiyekulturvarliklari.hrantdink.org/en/

33. An interactive geo-spatial visualization tool for GLAM (Galleries, Libraries, Archives, Museums). http://glammap.net/

34. Philippine Inventory of Cultural Properties and Historic Events. http://www.philippineheritagemap.org/map

35. Blaise JY, Dudek I (2011) Concentric time: enabling context + focus visual analysis of architectural changes, Proceedings of 19th International Symposium on Methodologies for Intelligent Systems. doi:10.1007/978-3-642-21916-0_67.

36. Kauppinen T, Mantegarib G, Paakkarinena P, Kuittinena H, Hyvonena E, Bandinic S (2010) Determining Relevance of Imprecise Temporal Intervals for Cultural Heritage Information Retrieval. International Journal of Human-Computer Studies, pp 549-560. doi:10.1016/j.ijhcs.2010.03.002.

37. Blaise JY, Dudek I (2013) Can infovis tools support the analysis of spatio-temporal diffusion patterns in historic architecture?. CAA series Computer applications and quantitative methods in archaeology, 40th annual conference of Computer applications and quantitative 
methods in archaeology, Mar 2013, Southampton, United Kingdom, Amsterdam university press, pp 367-378.

38. Shneiderman B (1996) The eyes have it: a task by data type taxonomy for information visualizations. Proceedings IEEE Symposium on Visual Languages, pp 336-343. doi:10.1016/b978-155860915-0/50046-9.

39. Leaflet open-source JavaScript library for mobile-friendly interactive maps. http://leafletjs.com/ 